\title{
Enraizamento de estacas herbáceas de quatro genótipos de kiwizeiros submetidas a tratamento com Ácido Indolbutírico
}

\author{
Leonardo Zucuni Guasso ${ }^{1,2, *}$ (D) Augusto Sassi ${ }^{2}$ (D), Samar Velho da Silveira ${ }^{4}$ (D), \\ Francisco Antonello Marodin ${ }^{3}$ (D), Paulo Vitor Dutra de Souza ${ }^{2}$ (D)
}

\author{
'Parte da dissertação do primeiro autor, Programa de Pós-Graduação em Fitotecnia, Universidade Federal do Rio Grande do Sul, \\ Porto Alegre, Rio Grande do Sul, Brasil. \\ 2Departamento de Horticultura e Silvicultura, Universidade Federal do Rio Grande do Sul. Av. Bento Gonçalves, 7712, CEP 91540-000, \\ Porto Alegre, Rio Grande do Sul, Brasil. \\ ${ }^{3}$ Secretaria do Meio Ambiente e Infraestrutura. Av. Borges de Medeiros, 261, CEP 90020-021, Porto Alegre, Rio Grande do Sul, Brasil \\ ${ }^{4}$ Empresa Brasileira de Pesquisa Agropecuária, Embrapa Uva e Vinho. Rua Livramento, 515, Caixa Postal 130 \\ CEP 95701-008, Bento Gonçalves, Rio Grande do Sul, Brasil \\ *Autor para correspondência: leonardo.guasso@ufrgs.br
}

Recebido em 19.IV.2019

Aceito em 28.VI.2020

DOI 10.21826/2446-82312020v75e2020016

RESUMO - A estaquia é uma alternativa para propagação de kiwizeiro, seja para a obtenção do porta-enxerto, ou enraizamento direto da variedade copa. Como é um método exclusivamente clonal, não há perda das características agronômicas de interesse. O objetivo foi avaliar o enraizamento de estacas herbáceas de 'Bruno', 'Elmwood' e 'Matua' (Actinidia deliciosa) e 'MG06' (Actinidia chinensis) submetidos a tratamento com Ácido Indolbutírico (AIB). As estacas foram imergidas, na sua base, nas concentrações de zero, 1.000, 2.000, 4.000, 6.000 e 8.000 $\mathrm{mgL}^{-1} \mathrm{de} \mathrm{AIB}_{\text {. Transcorridos }}$ 90 dias, avaliou-se: percentagem de estacas enraizadas, com calos e retenção foliar; comprimento das três maiores raízes; número de raízes e massa da matéria seca de raízes. O enraizamento de 'MG06' é superior a 'Elmwood' e 'Matua', não diferindo de 'Bruno'. 'Matua' apresentou o menor enraizamento. O AIB incrementa a percentagem de enraizamento, sendo que com a concentração estimada de $4.640 \mathrm{mgL}^{-1}$ pode-se obter $48,9 \%$ de estacas enraizadas.

Palavras-chave: auxinas, estaquia, kiwi, propagação vegetativa

ABSTRACT - Rooting of softwood cuttings of four genotypes of kiwifruit submitted to Indolbutyric Acid treatment. Cutting is an alternative kiwifruit propagation, to obtain rootstocks or to directly root its. As a clonal propagation method, there is no loss of desirable agronomic characteristics. This study was carried out to evaluate the rooting of softwood cuttings of kiwifruit 'Bruno', 'Elmwood' and 'Matua' (Actinidia deliciosa) and 'MG06' (Actinidia chinensis) submitted to indolebutyric acid (IBA) treatment. The cuttings were immersed, at their base, in concentrations 0, 1000, 2000, 4000,6000 and $8000 \mathrm{mgL}^{-1}$ of IBA. After 90 days, the following variables were evaluate: percentage of rooted cuttings, callus and leaf retention per cutting; average length of the three largest roots; average number of roots and root dry matter mass. The rooting of 'MG06' is higher than 'Elmwood' and 'Matua', not differing from 'Bruno'. 'Matua' presented the lowest rooting. The AIB increases the rooting percentage, and with an estimated concentration of $4,640 \mathrm{mgL}^{-1}$, it, can obtain $48.9 \%$ of rooted cuttings.

Keywords: auxin, cuttings, kiwifruit, vegetative propagation

\section{INTRODUÇÃO}

O gênero Actinidia tem como centro de origem o vale do rio Yangtzé, no sudeste da China, abrangendo diversas espécies, dentre as quais Actinidia deliciosa (A. Chev.) C. F. Liang \& A. R. Ferguson e Actinidia chinensis Planch, conhecidas como kiwi (Ferguson 2013). São espécies consideradas funcionalmente dioicas, apresentando plantas que atuam como femininas, devido a produção de pólen estéril e, masculinas, com ovários atrofiados (Huang 2016).

Durante a década de 1990 houve um grande interesse por esta frutífera, principalmente nos estados da região sul do Brasil. A cultura mostrou-se como uma alternativa aos cultivos tradicionais, apresentando alto potencial produtivo, baixos custos de produção, rusticidade e elevado preço de comercialização (Souza et al. 1996).

Contudo, o surgimento da murcha-do-kiwizeiro no sul do Brasil, causada pelo fungo Ceratocystis fimbriata Ellis \& Halst. (Sônego et al. 2010), aliada à carência de informações sobre tecnologias de produção nas diversas fases do cultivo, como propagação e produção de mudas; têm causado a redução da área plantada e ameaçado, inclusive, a sobrevivência da cultura nas regiões produtoras do Brasil. Ceratocystis fimbriata pode contaminar a planta pelas raízes, no solo, ou por ferimentos na parte aérea, como os decorrentes na poda. Atua diretamente no bloqueio do fluxo do sistema vascular, causando lesões de cor castanhoavermelhado nos tecidos internos do caule, murchamento e a queda das folhas e frutos, com posterior morte da 
planta (Piveta et al. 2016). Segundo Ferreira et al. (2017) a mortalidade das plantas nos pomares no município de Farroupilha é de 25 a $30 \%$ ao ano, já que todas variedades cultivadas apresentam suscetibilidade ao fungo.

Dentre as estratégias adotadas para o controle da referida doença, a seleção e multiplicação de material botânico resistente à murcha, além da produção de mudas livres de patógenos, estão entre os principais meios para que se possa estabelecer um novo sistema de produção de kiwi, possibilitando que a cultura alcance um nível tecnológico superior. Em estudo realizado por Pimenta (2018), avaliando a resistência de mudas seminais da cultivar 'Bruno' inoculadas com o fungo, foram obtidas plantas classificadas como resistentes, não apresentando sintomas característicos da doença.

Dessa forma, torna-se necessário modificar os métodos convencionais de propagação desta frutífera. No Brasil, a enxertia da copa em porta-enxertos oriundos de sementes provenientes da polinização cruzada, é o principal método de propagação do kiwizeiro. Isso resulta na variabilidade genética dos porta-enxertos, impossibilitando a multiplicação clonal de genótipos resistentes à doenças. Ademais, pode resultar em diferenças morfológicas e fisiológicas entre plantas no pomar, além de maior tempo de formação da muda (Silveira et al. 2012).

A estaquia pode ser uma alternativa viável, pois apresenta as vantagens se obter uma grande quantidade de mudas a partir de uma única planta matriz, ser de fácil e rápida execução. Além disso, confere maior uniformidade às plantas, por ser um método exclusivamente clonal, não ocorrendo a perda das características agronômicas de interesse (Xavier et al. 2013). Dessa forma, é um método de propagação com potencial para multiplicar material vegetal tolerante à murcha-do-kiwizeiro, com a possibilidade de ser utilizado tanto como porta-enxerto, como no enraizamento direto da variedade copa. Entretanto, a produção de mudas por estaquia também possui limitações, como é o caso da transmissão de patógenos, quando estacas são retiradas plantas matrizes doentes. Embora algumas doenças não se manifestem nas fases de viveiro, estas são introduzidas e disseminadas através do material de propagação (Fachinello et al. 2005).

Dentre os fatores que atuam para que ocorra sucesso no enraizamento, o genético é um dos mais significativos, já que a capacidade de uma estaca em emitir raízes é variável com a espécie e mesmo entre cultivares (Hartmann et al. 2011). Da mesma forma, a aplicação de fitorreguladores, sobretudo do grupo das auxinas, é uma maneira de estimular a formação de raízes em estacas, já que estes compostos estão envolvidos em diferentes rotas no metabolismo das plantas, como no estímulo da divisão celular e a dominância apical, assim como na ativação das células do cambio vascular e formação de raízes adventícias (Taiz \& Zeiger 2017). Dentre diversas auxinas, o Ácido Indolbutírico (AIB) é a mais utilizada, pois apresenta grande estabilidade e menor toxidez, proporcionando bons resultados para a maioria das espécies (Hartmann et al. 2011). Entretanto, a concentração ideal para aplicação é dependente do genótipo (Cunha et al. 2008). Outro fator que exerce forte influencia na diferenciação e desenvolvimento de raízes no processo de estaquia é a época do ano em que são coletadas as estaca. De acordo com Guasso (2018), estacas herbáceas de kiwizeiros coletadas no final da estação primaveril são as que apresentam maior percentagem de enraizamento.

Entre as cultivares de kiwizeiros produzidas no sul do Brasil, 'Bruno' (A. deliciosa) é a mais plantada, caracterizada por apresentar elevada rusticidade, produzindo de frutos com alto teor de vitamina C. A cultivar 'Elmwood' (A. deliciosa) destaca-se pela produtividade e tamanho dos frutos, possuindo médio requerimento em frio hibernal (aproximadamente 300 Horas de Frio). 'MG06' (A. chinensis), diferentemente das anteriores, produz frutos de polpa amarelada, bastante doces e aromáticos, sendo descrita como tendo boa adaptação climática, devido à reduzida exigência em frio no inverno. 'Matua' (A. deliciosa) é uma cultivar masculina, cuja floração começa precocemente, estendendo-se até o florescimento da maioria das cultivares produtoras (Simonetto \& Grellmann 1998, Silveira et al. 2012).

Neste contexto, o presente estudo teve como objetivo avaliar o enraizamento de estacas herbáceas de quatro genótipos de kiwizeiro ('Bruno', 'Elmwood', 'Matua' e 'MG06') submetidos a tratamento com diferentes concentrações de Ácido Índolbutírico (AIB).

\section{MATERIAL E MÉTODOS}

O estudo foi desenvolvido entre dezembro de 2016 e março de 2017, em ambiente protegido, nas dependências do Departamento de Horticultura e Silvicultura, da Faculdade de Agronomia, da Universidade Federal do Rio Grande do Sul, em Porto Alegre - RS.

Foram utilizados ramos oriundos de brotações herbáceas do ano, das cultivares femininas 'Bruno', 'Elmwood' e da cultivar polinizadora 'Matua', obtidas da coleção de kiwizeiros da Estação Experimental Agronômica da UFRGS, localizada em Eldorado do Sul - RS (3006’31.33" S e $51^{\circ} 40^{\prime} 08.40^{\prime \prime} \mathrm{W}$ ), instalado no ano 2000 . Também foi avaliada a cultivar feminina 'MG06', proveniente de pomar comercial localizado no município de Farroupilha - RS $\left(29^{\circ} 08^{\prime} 58^{\prime \prime} \mathrm{S}\right.$ e $\left.51^{\circ} 24^{\prime} 46.8^{\prime \prime} \mathrm{W}\right)$, instalado em 2001.

Coletou-se ramos de aproximadamente $1 \mathrm{~m}$ de comprimento, que foram envoltos em jornal umedecido, colocados dentro de sacos de polietileno de $100 \mathrm{~L}$ e rapidamente transportadas para o local de instalação do experimento.

As estacas herbáceas foram retiradas da parte mediana dos ramos e preparadas deixando-se duas gemas e metade da área de uma folha madura na gema superior. $\mathrm{O}$ comprimento médio de cada uma foi de $12 \mathrm{~cm}$ e diâmetro de aproximadamente $0,8 \mathrm{~cm}$. Na parte superior da estaca foi realizado um corte em bisel, assim como um corte transversal na base da mesma, logo abaixo da gema inferior. 
Em seguida, imergiu-se aproximadamente $2 \mathrm{~cm}$ da base de cada estaca em Ácido Indolbutírico (AIB), por um período de sete segundos. O fitorregulador foi utilizado na forma de solução hidroalcoólica, com concentrações variando conforme os tratamentos: zero (somente água deionizada); $1.000 ; 2.000 ; 4.000 ; 6.000$ e $8.000 \mathrm{mgL}^{-1} \mathrm{de}$ AIB, as quais foram obtidas por meio da dissolução de Ácido Indolbutírico $\left(\mathrm{C}_{3} \mathrm{H}_{13} \mathrm{NO}_{2}\right)$ p.a, com $98 \%$ de pureza $\left(\mathrm{NEON}^{\circledR}\right)$, em solvente composto por $52 \%$ de álcool etílico (p.a. de $96 \%$ de pureza), e posterirormente, completado o restante do volume desejado com água deionizada, conforme metodologia descrita por Hartmann et al. 2011.

Imediatamente após a aplicação dos fitorreguladores, aproximadamente $1 / 3$ da base de cada estaca foi introduzida em bandejas de poliestireno expandido (EPS), com 72 células, e volume de $120 \mathrm{~cm}^{3}$ por célula, contendo como substrato casca de arroz carbonizada, e colocadas em ambiente protegido, equipado com sistema de nebulização intermitente.

Os ciclos de aspersão constaram de 15 segundos, em intervalos de 4 minutos, durante o período diurno ( 7 às 19 horas), e de 15 segundos, em intervalos de 15 minutos, para o período noturno (19 às 7 horas), de forma a manter uma fina película de água sobre a superfície das folhas. A temperatura e umidade foram monitoradas durante todo o experimento, com dados obtidos através de termohigrômetro digital $\mathrm{AKSO}^{\circledR}$ (Fig. 1).

Transcorridos 90 dias da instalação do experimento verificou-se o efeito da auxina e do genótipo sobre o processo de formação das raízes adventícias. Para tanto, foram realizadas as seguintes avaliações: percentagem de estacas enraizadas (estacas com ao menos um primórdio radicial de, no mínimo, $1 \mathrm{~cm}$ de comprimento, podendo ou não apresentar calos); percentagem de estacas com calos (estacas que apresentavam em sua base, tecidos com massa celular indiferenciada); percentagem de retenção foliar (estacas que mantiveram a folha aderida ao final do período do experimento); comprimento médio das três maiores raízes (média do comprimento das três raízes mais longas por estaca enraizada); número médio de raízes (média do número total de raízes por estaca enraizada).

Posteriormente, avaliou-se a massa seca das raízes. Para tanto, foi realizada a lavagem das raízes com água corrente, e separadas da estaca. Após, as raízes foram acondicionadas em embalagens de papel e colocadas para secagem em estufa com circulação forçada de ar, regulada a uma temperatura de $65^{\circ} \mathrm{C}$, até atingir massa constante.

Os dados foram analisados segundo delineamento de blocos ao acaso, com arranjo fatorial (4 x 6), sendo quatro genótipos e seis concentrações de AIB; 4 blocos por combinação, e as unidades experimentais formadas por 12 estacas. Os dados foram submetidos à análise de variância e, quando apresentaram diferenças significativas pelo teste F, tiveram suas médias comparadas pelo teste de Tukey, ao nível de 5\% de probabilidade de erro e regressão. Os dados das variáveis expressas em porcentagem (enraizamento, calos e retenção foliar) foram transformados pela fórmula $\operatorname{arcsen} \sqrt{x} / 100$ e as oriundas de contagem (comprimento médio das três maiores raízes, e número médio de raízes) pela fórmula $\sqrt{ } \mathrm{x}+1$, sendo os dados apresentados em valores originais. Para a variável massa seca de raízes não foi realizada transformação. As análises estatísticas foram realizadas com auxílio do programa computacional Assistat 7.7.

\section{RESULTADOS E DISCUSSÃO}

O enraizamento das estacas sofreu influência dos genótipos e das concentrações de AIB, não havendo interação entre os fatores. A percentagem de enraizamento das estacas da cultivar 'MG06' foram superiores a 'Elmwood' e 'Matua', não diferindo estatisticamente de 'Bruno'. 'Matua' foi a que apresentou menor enraizamento entre as cultivares. Elmwood apresentou resultado intermediário, sendo menor que 'MG06' e maior que 'Matua'. (Tab. 1).

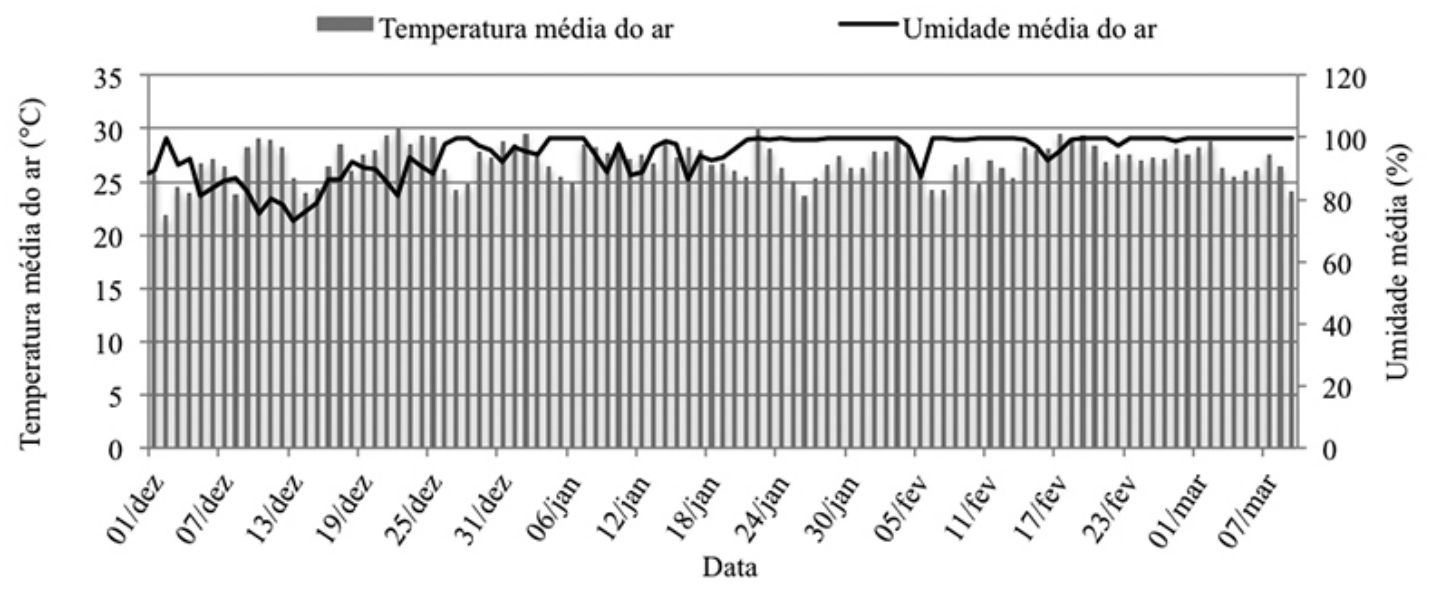

Fig. 1. Dados diários de temperatura e umidade média do ar no interior da câmara de nebulização, no período entre 01 de dezembro de 2016 e 07 de março de 2017. 
A formação de raízes adventícias em estacas é altamente dependente da cultivar e espécie, pois este processo é direta ou indiretamente controlado por genes. No entanto, os aspectos genéticos que influenciam na formação de raízes adventícias ainda são pouco estudados. Além disso, há presença ou não de cofatores de enraizamento nos tecidos, que também é variável com a espécie e dentro da espécie (Hartmann et al. 2011).

Como o material propagativo da cultivar 'MG06' foi coletado de pomar distinto das demais cultivares avaliados, este fato também pode haver contribuído para as diferenças encontradas, já que a formação de raízes em estacas é influenciado por um outros fatores, além do genético, e geralmente a interação destes é que melhor explica o enraizamento (Fachinello et al. 2005).

Fatores endógenos são específicos de determinada planta matriz, os quais podem-se citar a idade ontogenética e as condições fisiológicas no momento da coleta das estacas. Já os fatores exógenos são determinados pelas condições ambientas locais, como por exemplo, solo, temperatura e umidade. Por exemplo, estacas retiradas de plantas com déficit hídrico tendem a enraizar menos, por isso é importante que na época de coleta, os tecidos apresentem elevada turgidez, devido a sua vulnerabilidade à desidratação, sobretudo em estacas herbáceas (Xavier et al. 2013). Já em relação a condição nutricional, o conteúdo de carboidratos está positivamente correlacionado com o enraizamento e sobrevivência da estaca, pois as auxinas necessitam de carbono para realizar a iniciação das raízes, processo que requer energia. Da mesmo forma, o nitrogênio é importante para síntese de ácidos nucléicos e proteínas. De acordo com Cunha et al. (2009) relações C/N mais baixas podem prejudicar o enraizamento, pela elevada produção de parte aérea da estaca em detrimento das raízes. Fósforo, potássio, cálcio e magnésio são outros elementos fundamentais, que devem estar em equilíbrio para que haja sucesso no processo de estaquia, segundo estes autores.

Em relação a idade ontogenética da matriz, estacas retiradas de plantas mais velhas tendem a enraizar menos, possivelmente devido ao aumento do conteúdo endógeno de inibidores e redução de cofatores de enraizamentos observado em nas plantas com estágio avançado de maturidade (Hartmann et al. 2011). Entretanto, a pequena divergência de idade entre os pomares em que foram retiradas as estacas não justificaria as diferenças.

Semelhante ao presente estudo, onde foi verificado baixa percentagem de enraizamento na cultivar 'Matua', Zenginbal \& Özcan (2013) obtiveram 67\% de enraizamento com estacas coletadas no verão, com a concentração de $4.000 \mathrm{mgL}^{-1}$ de AIB. Embora 'Matua' tenha apresentado baixo enraizamento, esta é uma cultivar polinizadora, recomendando-se o seu plantio na proporção entre 1:5 a 1:8 (masculina:femininas) no pomar (Souza et al. 1996), sendo, portanto, muito importante sua oferta pelos viveiristas, pois são imprescindíveis para viabilizar pomares altamente produtivos.

Em relação às doses de AIB, observou-se um padrão de comportamento quadrático para o percentual de enraizamento para todas as cultivares avaliadas, onde uma máxima eficiência foi obtida com a concentração calculada de $4.640 \mathrm{mgL}^{-1}$ de AIB e, após, passou a ser prejudicial (Fig. 2). O enraizamento médio das estacas herbáceas em ausência de AIB foi de apenas 16,4\%, enquanto que com a utilização de auxinas, atingiu $48,9 \%$ na concentração de maior eficiência. Isso demonstra que o kiwizeiro é uma espécie de difícil enraizamento, já que na ausência de fitorreguladores, apresentou baixa percentagem de estacas enraizadas. Além disso, denota a importância da correta escolha da concentração de auxina exógena, pois significa maior eficiência e economicidade.

Erturk et al. (2010), avaliando o enraizamento de estacas da cultivar 'Hayward', coletadas no verão, constatou que a concentração mais efetiva foi de $4.000 \mathrm{mgL}^{-1} \mathrm{de}$ AIB, obtendo resultados semelhantes ao presente estudo. De acordo com Fachinello et al. (2005), quando são utilizadas auxinas exógenas, há um aumento no enraizamento até um valor máximo na concentração do fitorregulador, a partir do qual, qualquer incremento tem efeito inibitório, assim como elevadas concentrações de auxinas podem resultar em inibição no enraizamento, evidenciado no presente estudo.

A formação de calo na base das estacas apresentou um modelo linear decrescente em relação às concentrações de AIB aplicadas (Fig. 3), não havendo diferenças significativas entre os genótipos (Tab. 1).

Mattiuz \& Fachinello (1996), não encontraram diferenças significativas em percentagem de formação

Tabela 1. Percentagem de estacas enraizadas (PEE), percentagem de estacas com calos (PEC), percentagem de retenção foliar (PRF), comprimento médio das três maiores raízes $(\mathrm{CR})$ de diferentes genótipos de kiwizeiros.

\begin{tabular}{|c|c|c|c|c|}
\hline \multirow{2}{*}{ Genótipo } & \multicolumn{4}{|c|}{ Variável Analisada* } \\
\hline & $\operatorname{PEE}(\%)^{1}$ & $\operatorname{PEC}(\%)^{1}$ & $\operatorname{PRF}(\%)^{1}$ & $\mathrm{CR}(\mathrm{cm})^{2}$ \\
\hline MG06 & $35,8 \mathrm{a}^{*}$ & $16,0^{\mathrm{ns}}$ & $42,6 \mathrm{a}$ & $2,9 \mathrm{c}$ \\
\hline Bruno & $32,9 \mathrm{ab}$ & 19,6 & $35,3 \mathrm{ab}$ & $3,8 \mathrm{~b}$ \\
\hline Elmwood & $25,7 \mathrm{~b}$ & 17,1 & $29,5 \mathrm{~b}$ & $4,8 \mathrm{a}$ \\
\hline Matua & $20,5 \mathrm{c}$ & 18,1 & $14,5 \mathrm{c}$ & $3,8 \mathrm{~b}$ \\
\hline C.V. (\%) & 26,1 & 18,1 & 25,7 & 28,3 \\
\hline
\end{tabular}

* Médias seguidas da mesma letra na coluna não diferem significativamente entre si, pelo teste de Tukey, a 5\% de probabilidade de erro.

${ }^{1}$ Dados transformados pelo arcsen $\sqrt{\mathrm{x}} / 100 ;{ }^{2}$ Dados transformados pela fórmula $\sqrt{\mathrm{x}}+1$. 
de calos entre cultivares 'Bruno' e 'Tomuri' coletadas em diferentes épocas, verificando uma relação inversa entre enraizamento e formação de calos, como no presente estudo, onde foi obtida uma correlação negativa $(-0,8794)$ entre estes parâmetros.

O corte realizado na base da estaca provoca um dano nos feixes vasculares, ocorrendo, posteriormente, a formação de uma massa celular de parênquima para constituir o tecido de cicatrização, denominado calo. A formação de calo e raízes podem ser processos totalmente independentes, podendo o calo ser um indício da formação de raízes ou ser um processo anterior. No presente estudo verificouse que as raízes surgiram predominantemente nos locais onde foram realizados os cortes ou logo acima deles, mas nunca nos calos, constituindo neste caso, possivelmente, uma barreira física para emissão das raízes (Hartmann et al. 2011).

As concentrações de AIB não influenciaram o percentual de estacas que mantiveram as folhas retidas após o período

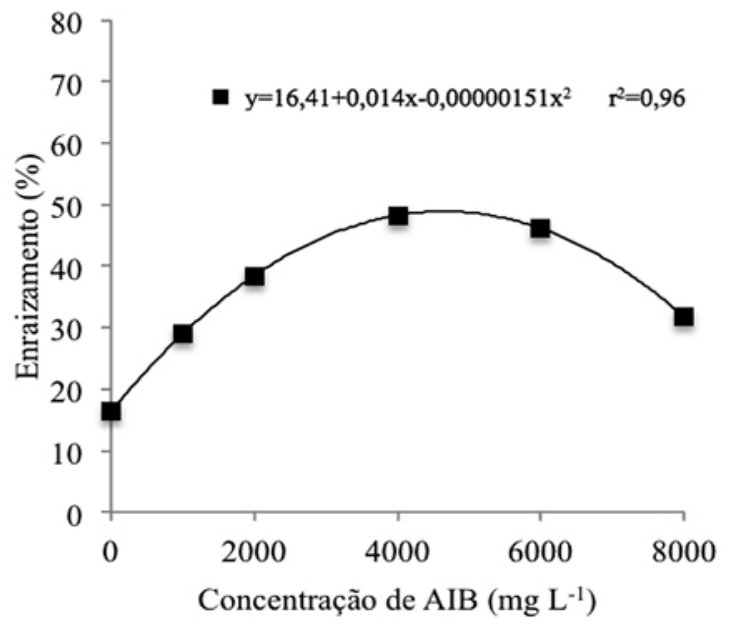

Fig. 2. Percentagem de enraizamento de estacas de kiwizeiros (média de quatro genótipos), submetidas a tratamento com diferentes concentrações de ácido indolbutírico (AIB)

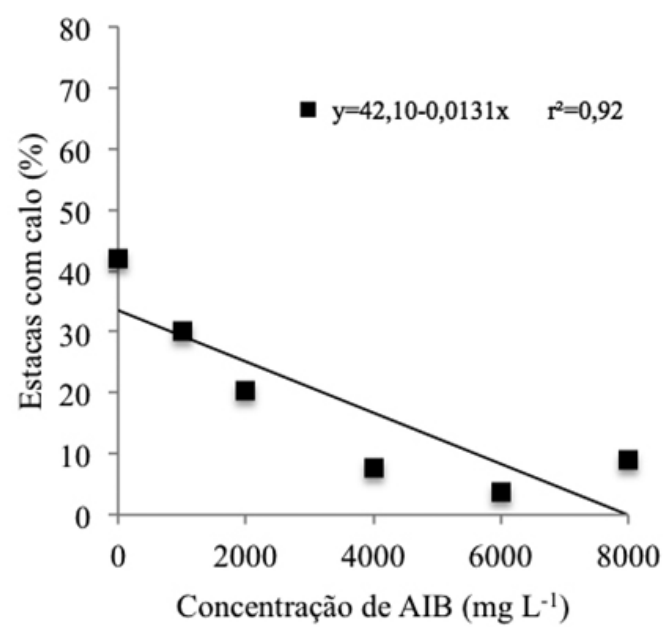

Fig. 3. Percentagem de formação de calo em estacas de kiwizeiro (média de quatro genótipos), submetidas a tratamento com diferentes concentrações de ácido indolbutírico (AIB). de estaquia (retenção foliar). . Segundo Trueman \& Adkins (2013), as auxinas, como o AIB, sobretudo quando utilizadas em altas concentrações, podem induzir a abscisão foliar pela produção de etileno, entretanto, esse comportamento não foi observado no presente estudo.

Em relação aos genótipos, 'Matua' foi o que apresentou maior percentagem de estacas que perderam as folhas, enquanto que para 'MG06' foi observado o contrário (Tab. 1). A retenção foliar correlacionou-se positivamente com o percentual de enraizamento $(0,8337)$, denotando a importância da presença de folhas maduras na estaquia herbácea. As folhas da cultivar 'Matua', no momento da coleta, apresentavam características morfofisiológicas, como turgor, idade e sanidade, semelhante às demais cultivares avaliadas. Entretanto, nos dias iniciais da instalação do experimento, apresentaram murcha, com posterior necrose e abscisão da estaca. Este comportamento não foi observado com a mesma intensidade nos demais genótipos. Possivelmente, fatores genéticos estão ligados à retenção foliar. De acordo com Ono \& Rodrigues (1996), as folhas podem servir como fonte de reservas, que são translocadas até a base da estaca. Da mesma forma, a presença de folhas e gemas em estacas herbáceas torna-se indispensável para a formação de raízes, pois é um sítio de produção de auxinas e outros cofatores de enraizamento, além da manutenção do processo fotossintético (Hartmann et al. 2011).

Em relação ao comprimento médio das três maiores raízes por estaca, observaram-se diferenças significativas entre as doses de AIB e entre genótipos, porém não houve interação entre os fatores. A cultivar 'Elmwood' foi a que apresentou raízes mais longas, enquanto 'MG06' mais curtas, sendo observado comprimento intermediário nas demais cultivares (Tab. 1). Esta variável apresentou um comportamento quadrático positivo em relação às doses de auxinas para todas as cultivares, saturando a resposta na concentração calculada de $4.515 \mathrm{mgL}^{-1}$ de AIB (Fig. 4).

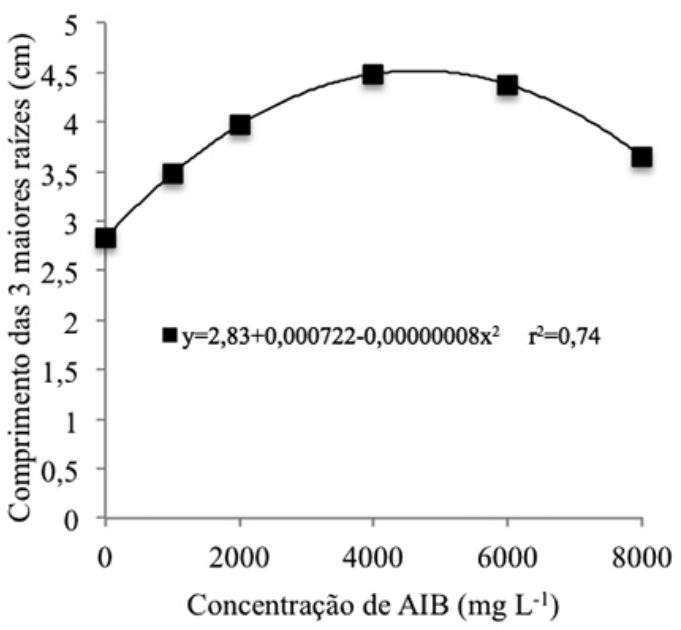

Fig. 4. Comprimento médio das três maiores raízes por estaca (média de quatro genótipos) de kiwizeiro, submetidas a tratamento com diferentes concentrações de ácido indolbutírico (AIB). 


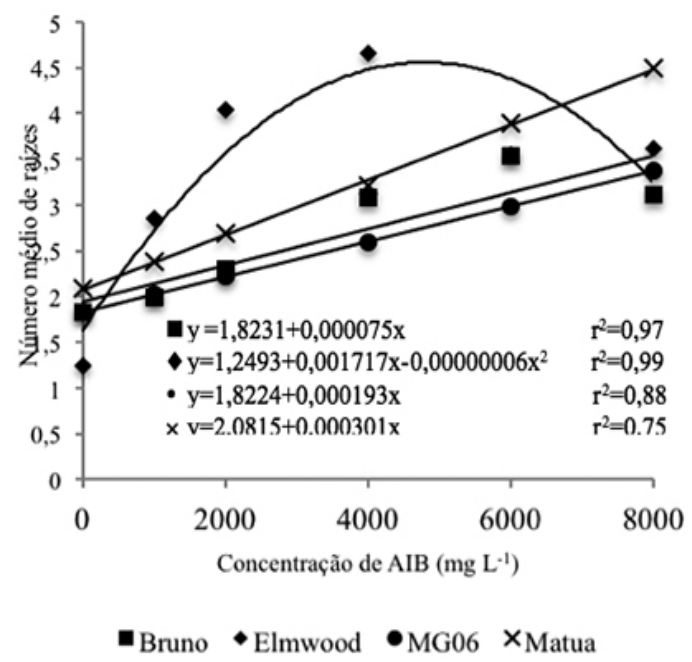

Fig. 5. Número médio de raízes primárias por estaca, em quatro genótipos de kiwizeiro, submetidas a tratamento com diferentes concentrações de ácido indolbutírico (AIB).

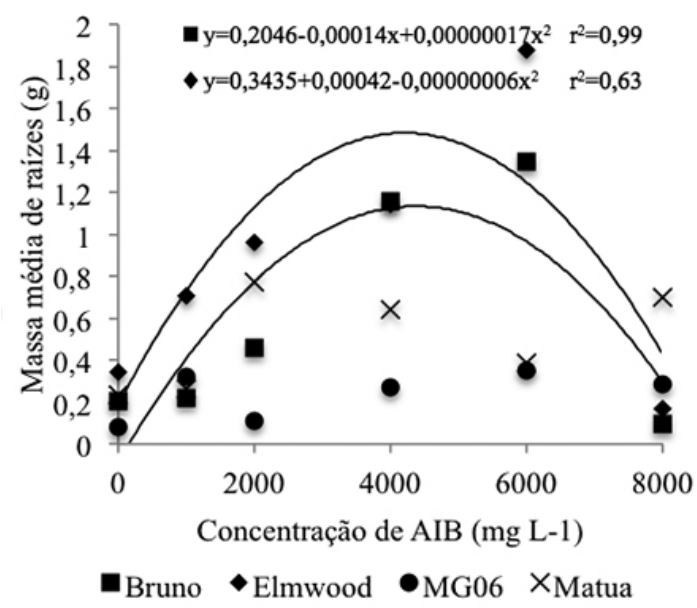

Fig. 6. Massa da matéria seca média de raízes, em quatro genótipos de kiwizeiro, submetidos a tratamento com diferentes concentrações de ácido indolbutírico (AIB).

No que concerne ao número médio de raízes primárias emitidas por estaca, verificou-se efeitos significativos entre as concentrações de auxinas e genótipos, havendo interação entre os fatores. Esta variável incrementou linearmente com as concentrações de AIB nas cultivares 'Bruno', 'MG06' e 'Matua'. Para 'Elmwood', foi observado um comportamento quadrático, onde o número de raízes foi crescente até a concentração calculada de $4.308 \mathrm{mgL}^{-1}$, a partir da qual, reduziu (Fig. 5).

'Elmwood' e 'Matua' chegaram a apresentar 4,5 raízes por estaca na dose mais efetiva, enquanto que 'Bruno' e 'MG06' apresentaram até 3,5 raízes por estaca.
Um reduzido número de raízes adventícias em estacas é verificado nos diferentes genótipos de kiwi, podendo indicar a baixa habilidade desta frutífera em relação à esta variável. Pio et al. (2010) observaram que a cultivar 'Alisson' emitiu 3,3 raízes por estaca lenhosa (enraizamento $72,5 \%$ ), enquanto que 'Tomuri' e 'Bruno' apresentaram 2,0 raízes (35 e 46,7\% de enraizamento, respectivamente), mesmo com a utilização de auxina. Mattiuz \& Fachinello (1996), observaram um efeito positivo da aplicação de AIB para o número de raízes por estacas de 'Bruno', obtendo aproximadamente 3 raízes por estaca na concentração mais efetiva de auxina. $\mathrm{Na}$ literatura não há trabalhos que especifiquem comprimento e número de raízes em estacas de kiwizeiro necessários para a formação de uma muda de qualidade. Para frutíferas em geral, durante o período de enraizamento, a qualidade do sistema radicular está indiretamente relacionada com número de raízes emitidas por estaca, sendo um indicativo da capacidade da muda ter um melhor desenvolvimento inicial quando é transplantada para o pomar, resultando em maior produtividade (Fachinello et al. 2005).

Verificou-se uma interação significativa entre os genótipos e as concentrações de auxinas para o fator massa seca média de raízes. Nas estacas das cultivares 'Bruno' e 'Elmwood' houve um comportamento quadrático em relação aos incrementos nas doses de AIB, enquanto para as demais cultivares não houve efeito significativo da aplicação de auxinas. 'MG06' apresentou menor massa de matéria seca de raízes, comparativamente aos demais (Fig. 6). Manfroi et al. (1997) encontraram um aumento linear na massa seca de raízes em estacas semilenhosas da cultivar 'Monty', com o incremento das doses de AIB até $8.000 \mathrm{mgL}^{-1}$.

Nos tratamentos sem o emprego de auxinas ou em baixas concentrações, foi verificado menor percentual de estacas enraizadas e, quando estas enraizaram, o sistema radicular era bastante reduzido, podendo resultar em baixa sobrevivência quando transplantadas para o pomar. De maneira geral, os resultados demonstraram que o uso do AIB interferiu de forma quantitativa, expresso pelo percentual de estacas enraizadas, e também qualitativamente, formando um sistema radicular com maior comprimento, número e massa da matéria seca de raízes, permitindo aumentar a qualidade da muda produzida. Assim, o enraizamento de 'MG06' é superior a 'Elmwood' e 'Matua', não diferindo de 'Bruno'. 'Matua' apresenta o menor enraizamento entre as cultivares analisadas. O AIB incrementa a percentagem de enraizamento, sendo que com a concentração estimada de $4.640 \mathrm{mgL}^{-1}$ pode-se obter $48,9 \%$ de estacas enraizadas.

\section{AGRADECIMENTOS}

À Capes (Coordenação de Aperfeiçoamento do Pessoal de Nível Superior) pela concessão da bolsa de mestrado do primeiro autor e à Embrapa Uva e Vinho pelo apoio financeiro. 


\section{REFERÊNCIAS}

Cunha, A. C. M. C. M., Wendling, I. \& Souza Júnior, L. 2008. Miniestaquia em sistema de hidroponia e em tubetes de corticeira-do-mato. Ciência Florestal 18:85-92.

Cunha, A. C. M. M., Paiva, H. N., Xavier, A., \& Otoni, W. C. 2009. Papel da nutrição mineral na formação de raízes adventícias em plantas lenhosas. Pesquisa Florestal Brasileira 58: 35-47.

Erturk, Y., Ercisli, S., Haznedar, A. \& Cakmakci, R. 2010. Efects of plant growth promoting rhizobacteria (PGPR) on rooting and root growth of kiwifruit (Actinidia deliciosa) stem cuttings. Biological Research 43:91-98.

Fachinello, J. C., Hoffmann, A. \& Nachtigal, J. C. 2005. Propagação de plantas frutíferas. Embrapa Informação Tecnológica, Brasília. 221 p.

Ferguson, A. R. 2013. Kiwifruit: the wild and the cultivated plants. In Advances in food and nutrition research (M. Boland \& P. J. Moughan eds). Academic Press, Cambridge, p. 15-32.

Ferreira M. A., Harrington T. C, Piveta G., \& Alfenas A.C. 2017. Genetic variability suggests that three populations of Ceratocystis fimbriata are responsible for the Ceratocystis wilt epidemic on kiwifruit in Brazil. Tropical Plant Pathology 42(2):86-95.

Guasso, L. Z. 2018. Propagação de kiwizeiros por estaquia. Dissertação 82 f., Universidade Federal do Rio Grande do Sul, Rio Grande do Sul.

Hartmann, H. T., Kester, D. E., Davies Jr, F. T. \& Geneve, R. L. 2011. Plant Propagation: Principles and Practices. Pearson, New Jersey. 928 p.

Huang, H. 2016. Kiwifruit: The Genus Actinidia. Academic Press. Beijing. $334 \mathrm{p}$

Manfroi, V., Francisconi, A. H. D., Barradas, C. I. N. \& Seibert, E. 1997. Efeito do AIB sobre o enraizamento e desenvolvimento de estacas de quivi (Actinidia deliciosa). Ciência Rural 27:43-46.

Mattiuz, B. H. \& Fachinello, J. C. 1996. Enraizamento de estacas de kiwi Actinidia deliciosa (A. Chev) C. F. Liang \& A. R. Fergunson var. Deliciosa. Pesquisa Agropecuária Brasileira 31(7):503-508.

Ono, E. O. \& Rodrigues, J. D. 1996. Aspectos da fisiologia do enraizamento de estacas caulinares. Fundação de Apoio a Pesquisa,
Ensino e Extensão (Faculdade de Ciências Agrárias e Veterinárias - Universidade Estadual Paulista 'Júlio de Mesquita Filho'), Jaboticabal. $83 \mathrm{p}$.

Pio, R., Costa, F. C., Curi, P. N. \& Moura, P. H. A. 2010. Enraizamento de estacas lenhosas de cultivares de kiwizeiro. Scientia Agraria 11(3):271-274.

Pimenta, L., V., A. 2018. Estrutura Genética da População de Ceratocystis Fimbriata Associada a Kiwi e Avaliação da Resistência do Hospedeiro À Murcha-de-Ceratocystis. Dissertação 77 f., Universidade Federal de Viçosa, Minas Gerais.

Piveta G., Ferreira M. A., Muniz M. F., Valdetaro D. C. O. F., ValdebenitoSanhueza R. M., Harrington T. C. \& Alfenas A. C. 2016 Ceratocystis fimbriata on Kiwifruit (Actnidia spp.) in Brazil. New Zealand Journal of Crop \& Horticultural Science 44:13-24.

Silveira, S. V., Anzanello, R., Simonetto, P. R., Gava, R., Garrido, L. R., Santos, R. S. S. \& Girardi, C. L. 2012. Aspectos técnicos da produção de quivi. Embrapa Uva e Vinho, Bento Gonçalves. 82 p.

Simonetto, P. R. \& Grellmann, E. O. 1998. Cultivares de kiwi com potencial de produção na região da Serra do Nordeste do Rio Grande do Sul. Fepagro, Porto Alegre. $19 \mathrm{p}$.

Sônego, O. R., Ferrera, M. A., Valdebenito-Sanhueza, R. M., Garrido, L. D. R. \& Alfenas, A. C. 2010. Primeiro relato da murcha-de-ceratocystis em kiwi. Tropical Plant Pathology 35:233.

Souza, P. V. D., Marodin, G. A. B. \& Barradas, C. I. N. 1996. Cultura do quivi. Cinco Continentes, Porto Alegre, $104 \mathrm{p}$.

Taiz, L., \& Zeiger, E. 2017. Fisiologia e Desenvolvimento Vegetal. Artmed, Porto Alegre. 888 p.

Trueman, S.J. \& Adkins, M.F. 2013. Effect of aminoethoxyvinylglycine and 1-methylcyclopropene on leaf abscission and root formation in Corymbia and Eucalyptus cuttings. Scientia Horticulturae 161:1-7.

Xavier, A., Wendling, I., Silva, R. L 2013. Silvicultura Clonal: Princípios e Técnicas, Editora Universidade Federal de Viçosa, Viçosa. 279 p.

Zenginbal, H., \& Özcan, M. 2013. The Effects Of Cutting Time, Bud Number and IBA Concentration on the Cutting on Rooting of Kiwifruit. Anadolu Journal of Agricultural Sciences 29:1-11. 